\title{
Prevalence of High Risk Pregnant Women Who Attend Antenatal Care and Associated Factors in Jimma Medical Center, Jimma Town, South Western Ethiopia
}

\author{
Jemila Nesro ${ }^{1 *}$, Midhagsa Dhinsa ${ }^{2}$ and Melkamu Gelan ${ }^{1}$ \\ ${ }^{1}$ School of Nursing and Midwifery, Jimma University, Ethiopia \\ ${ }^{2}$ School of Nursing, Dilla University, Ethiopia
}

*Corresponding author: Jemila Nesro, School of Nursing and Midwifery, Jimma University, Ethiopia

\begin{abstract}
Background: Around 303,000 women and adolescent girls pass on from pregnancy and childbirth-related complications in 2015 and $99 \%$ of these deaths occur in developing countries. That same year, 2.6 million babies were stillborn. Almost all of the maternal deaths $(99 \%)$, child deaths $(98 \%)$, Sixty percent of the stillbirths (1.46 million) occurred during the antepartum period and mainly due to untreated maternal infection, hypertension, and poor fetal growth and occurred in low- and middle-income countries. These maternal deaths could have been prevented if the pregnant women or adolescent girls had been able to access quality antenatal care. A high-risk pregnancy refers to anything that situates the mother, fetus, or neonate at increased risk for morbidity or mortality during pregnancy or childbirth, even during postpartum.
\end{abstract}

Methods: Facility based cross-sectional study was conducted to determine the prevalence of high risk among pregnant women. Non-probability, Convenient sampling technique was used to collect the data by using structured, closed ended and pretested questionnaire and the data collection will be conducted by interviewing the study participants. Data was analyzed by using tally sheets and computer. The association between variables was analyzed using Chi-square test. The result was presented in tables and figures.

Result: Out of 314 pregnant mothers with response rate of $100 \% 47(15.0 \%)$ were < 19 years, $261(83.12 \%)$ were 20 34 years and $6(1.9 \%)$ were $\geq 35$ years. While, $60(19.1 \%)$ of the study participants were primigravida mothers and the rest were multigravida. In addition, $210(66.9 \%)$ were at their first visit in first trimester, $77(24.5 \%)$ were at second trimester, and $27(8.6 \%)$ were at third trimester. Among all, the prevalence of high risk pregnancy was $83(26.43 \%)$. The leading risk factor identified in the index pregnancies were
HTN 40 (12.5\%), anemia 15 (4.8\%), 12 (3.8\%) had DM, 9 $(2.87 \%)$ had $\mathrm{APH}, 7(2.2 \%)$ had malpresentation.

Conclusion: From the total of study participant's hypertension, anemia, DM, APH and mal presentation founded as the major health problems. Expanding the utilization of antenatal care, early detection, problem identification and management for all pregnant women should be under taken.

\section{Keywords}

High risk pregnancy, Antenatal care, Jimma medical center

\section{Abbreviations}

ANC: Antenatal Care; APH: Ante Partum Hemorrhage; CBE: Community Based Education; GDM: Gestational Diabetes Mellitus; JU: Jimma University; JMC: Jimma Medical Center; $\mathrm{MCH}$ : Maternal and Child Health; $\mathrm{PPH}$ : Postpartum Hemorrhage; SBA: Skilled Birth Attendant; SRP: Student Research Program; WHO: World Health Organization

\section{Introduction}

Around 303,000 women and adolescent girls pass on from pregnancy and childbirth-related complications in 2015 and $99 \%$ of these deaths occur in developing countries. That same year, 2.6 million babies were stillborn. Almost all of the maternal deaths $(99 \%)$, child deaths (98\%), Sixty percent of the stillbirths ( 1.46 million) occurred during the antepartum period and mainly due to untreated maternal infection, hypertension, and poor fetal growth and occurred in low- and middleincome countries. These maternal deaths could have been prevented if the pregnant women or adolescent

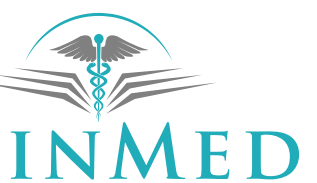

INTERNATIONAL LIBRARY

Citation: Nesro J, Dhinsa M, Gelan M (2021) Prevalence of High Risk Pregnant Women Who Attend Antenatal Care and Associated Factors in Jimma Medical Center, Jimma Town, South Western Ethiopia. Int J Womens Health Wellness 7:133. doi.org/10.23937/2474-1353/1510133

Accepted: December 29, 2021: Published: December 31, 2021

Copyright: (C) 2021 Nesro J, et al. This is an open-access article distributed under the terms of the Creative Commons Attribution License, which permits unrestricted use, distribution, and reproduction in any medium, provided the original author and source are credited. 
girls had been able to access quality antenatal care. Every year nearly 5,29,000 women die globally due to pregnancy related causes. For each death nearly 118 women suffer from life threatening events or morbidity [1-4].

A high risk pregnancy is anything that put the mother, fetus or neonate at increased risk for morbidity or mortality during pregnancy or childbirth and it is defined as one which is complicated by factor or factors that adversely affect the pregnancy outcome (maternal, fetus or both). Although only $10-30 \%$ of the mothers seen in antenatal period can be classified as high risk but they account for $70-80 \%$ of perinatal mortality and morbidity [5]. Antenatal women with the following conditions were categorized under high-risk pregnancy: Severe anaemia with haemoglobin level $<7 \mathrm{~g} / \mathrm{dl}$, Hypertensive disorder in pregnancy (blood pressure $>140 / 90 \mathrm{mmHg}$ ), Pregnant women positive for HIV/syphilis, Hypothyroidism (thyroid-stimulating hormone values - first trimester: $0.1-2.5 \mathrm{mIU} / \mathrm{L}$, second trimester: $0.2-3 \mathrm{mIU} / \mathrm{L}$, and third trimester: $0.3-3 \mathrm{mIU} /$ L),Gestational diabetes mellitus (glucose challenge test $\geq 140 \mathrm{mg} / \mathrm{dl}$ ), Twin pregnancy or multiple pregnancy, Previous history of lower segment caesarean section, Younger primi (age $<20$ years) or elderly gravida (age > 35 years), Malpresentation, Bad obstetric history (history of congenital malformation, stillbirth, abortion, premature birth, and obstructed labor), Rh incompatibility, Low-lying placenta or placenta previa [1,2,5-8].

But little is known about the current magnitude and associated factors among pregnant women in Ethiopia and specifically in Jimma. This study therefore aims to fill this gap by assessing the current status and factors associated with high risk in pregnancy women attending ANC follow up at JMC (Jimma Medical Center).

\section{Methods and Materials}

\section{Study area and period}

Jimma Medical Center was established in 1930 E.C by Italian invaders for the service of their soldiers and located at about $346 \mathrm{Km}$ in south west of capital city, Addis Ababa. JMC is the only specialized referral hospital in south west Ethiopia. It is situated to the East of Jimma town at about $3 \mathrm{~km}$ from the down town Jimma municipality. The hospital gives service to about 11 million peoples living in a wide catchments area of about $250 \mathrm{~km}$ radius in south west Ethiopia. It is a training center for about more than 1,000 health science students each year. JMC has four major departments: Internal Medicine, Surgery, Gynecology/Obstetrics and pediatrics and five minor departments. The service provided by gynecology and obstetrics department is divided in to four sections. Pregnant mother get antenatal care in $\mathrm{MCH}$ department and ladies with various gynecologic problems are seen in gynecologic outpatient department. Currently there are six senior doctors, 13 residents, 38 medical interns, 5 midwives and 25 clinical nurses working in the department. The study was conducted in JMC from April 15-May 15/2019.

\section{Study design}

Facility based Cross sectional study was conducted.

\section{Source of population}

All pregnant women attending ANC follow up at JMC.

\section{Study population}

All pregnant women who attended antenatal care service at JMC during the data collection period.

\section{Study unit}

Each pregnant woman who were fulfil the inclusion criteria during study period.

\section{Sample size determination and sampling procedure}

The sample size was determined using the single population proportion formula by considering 30\% proportion from the study conducted in India [1]. With a marginal error of $5 \%$ between the sample and the population at $95 \%$ confidence level.Since the total numbers of pregnant women attend ANC follow up at JMC are less than 10,000 so we used correction formula. Plus considering $10 \%$ non-response rate then the final sample size was 314 .

The subject was selected using convenient sampling method. The sample size selected were 314 and the number of working day per month is 22 , then by dividing 314 for $22(314 / 22=15)$, means 15 women who have interest were interviewed daily. Then, 8 women were interviewed by morning and 7 women by afternoon.

\section{Measurement}

Data was collected using a pretested-interviewer administered structured questionnaire adapted and customized from validated questionnaires and supported by medical record, laboratory request paper and report from other health institution. The questionnaire was adapted from English and translated to Amharic and Afan Oromo (local languages) and translated back to English by language experts to ensure its consistency. The structured questionnaire was prepared after review of relevant literature and ANC follow up guideline line and protocol (1,2, and 25). The questionnaire is closed ended and it have three parts. The first, second, and third are sociodemographic, questions of high risks, and questions of lab investigation respectively.

Before the actual data collection the questionnaire (tool) was pretested for validity and reliability in $16(5 \%)$ pregnant women who attended ANC follow up at Shenen Gibe Hospital which was not selected for the actual study. 


\section{Data collection}

Two degree data collectors who are midwives were recruited. Training was given before the data collection period on objectives of the study and questionnaires for two days. Data was collected by using a pretested structured questionnaire supported by reviewing of medical record, laboratory request paper and reports for pregnant women from other health institution. In addition, continuous follow up and supervision was made to the data collectors by the principal investigator throughout the data collection period.

\section{Data analysis}

The data was cleaned, coded and checked for completeness and the incomplete questionnaires were discarded. Data was analyzed by using tally sheets and computers. Data analysis includes descriptive statistics, including frequency, percentage, mean and standard deviation. The association between variables was analyzed using Chi-square test. Variables with P-value of less than 0.05 in binary logistic regression analysis were considered as statistically significant. Finally the result will be presented in tables, figures and by statement if necessarily.

\section{Operational definitions}

High risk pregnancy: Refers to pregnancy women who come to JMC for ANC follow up and pregnancy complicated by conditions such as Anemia, Preeclampsia, Gestational diabetes mellitus, APH, malpresentation, multiple pregnancy, and age of 18 years or less that adversely affect the maternal and fetal outcome.

\section{Ethical considerations}

A permission letter was written from school of nursing and midwifery faculty of health science, Jimma University. Permission was obtained from respective health institutions and written consent (signed on the informed consent sheet) was obtained from pregnant mother attending antenatal care service after discussing the objective of the study. The right of the respondents to refuse answering for few or all of the questions were also be respected. All the information about the study participants, health care providers and health sectors remain confidentially and shared only by the study team.

\section{Result}

\section{Socio-demographic characteristics}

Out of 314 pregnant mothers with response rate of $99.9 \%$. From those majority of the respondents $261(83.12 \%)$ were $20-34$ years and $60(19.1 \%)$ of the attendants were primigravida mothers. Regarding educational status $110(35 \%)$ were learn grade 7-12. Among all 253(80.57\%) were married and $120(38.21 \%)$ were House wife. Additionally, 83 (26.43\%) had at least one problem related to pregnancy such as $40(12.7 \%)$ were diagnosed for HTN, 15(4.8\%) were anemic, $12(3.8 \%)$ had DM, 9(2.87\%) had APH, 7(2.2\%) had malpresentation, and $14(4.46 \%)$ had chronic illness. This study showed that age, occupational status, trimester, parity, educational status, and monthly income have association with risky factors of women (Table 1).

\section{Distribution of pregnant mother who attended ANC at JMC and risk in index pregnancy}

Out of 314 pregnant mothers who attended JMC for ANC service 210 (66.9\%) were first visit at first trimester. Also regarding gravidity 60 (19.1\%) were primigravida and majority of them $40(12.7 \%)$ were diagnosed for pregnancy induced HTN. From those who has HTN 5 $(1.6 \%), 11(3.5 \%)$, and $24(7.64 \%)$ were diagnosed at 1TM, 2TM, and 3TM respectively (Figure 1 and Figure 2).

Out of 314 pregnant mothers who attended JMC for ANC service 17 (5.41\%) had $\mathrm{Hx}$ of abortion and the reason for abortion is unexpected Px, severe infection, and complicated $\mathrm{Px} \mathrm{w/C}$ is $11(3.5 \%), 5(1.6 \%)$ and $2(0.63 \%)$ respectively. Also $13(4.14 \%)$ of abortion performed by professional and $4(1.27 \%)$ were performed by traditional practitionare. In addition to this $14(4.46 \%)$ had $\mathrm{Hx}$ of operative delivery, and $11(3.5 \%)$ had $\mathrm{Hx}$ of multiple pregnancy (Figure 3).

N.B. Previous risk factors may not occur in the index pregnancy.

Out of 314 pregnant mothers who attended JMC for ANC service $23(7.32 \%)$ of them have family Hx of HTN, $10(3.18 \%)$ have family $\mathrm{Hx}$ of $\mathrm{DM}, 7(2.2 \%)$ have family $\mathrm{Hx}$ of $\mathrm{HD}, 2(0.64 \%)$ have family $\mathrm{Hx}$ of asthma, and $17(5.4 \%)$ have family $\mathrm{Hx}$ of other Disease (Figure 4).

Out of 314 pregnant mothers who attended JMC for ANC service 80(25.47\%), 30(9.55\%), 93(29.61\%) are consume alcohol, smoke cigarette, and chew chat respectively (Figure 5).

Out of 314 pregnant mothers who attended JMC for ANC service 230(73.25\%) has $\mathrm{Hx}$ of contraceptive use, 144(45.85\%) consume high salt during Px, 249(79.3\%) get Iron supplementation on current Px, 230(73.25\%) eat fruit and vegetables, and $253(80.57 \%)$ exercise regularly (Figure 6).

Out of 314 pregnant mothers who attended JMC for ANC service $33(10.5 \%), 191(60.83 \%)$, and $90(28.66 \%)$ of women has BMI OF $<18.5,18.5-24.9, \geq 25$ respectively (Figure 7).

\section{Factors associated with high risk during pregnancy}

Chi square test showed that age, occupational status, trimester, parity, educational status, and monthly income shows association with high risk during pregnancy at Jimma medical center, Jimma town, south western Ethiopia, 2019 (Table 2). 
Table 1: Socio demographic characteristic of pregnant mother who attended ANC department of JMC Jimma town, south western Ethiopia, 2019.

\begin{tabular}{|c|c|c|c|}
\hline Variables & Characteristic & $\mathbf{N}^{\circ}$ & Percentage (\%) \\
\hline \multirow{6}{*}{$\begin{array}{l}\text { Age } \\
\text { (in Years) }\end{array}$} & $15-19$ & 47 & 15 \\
\hline & $20-24$ & 110 & 35.06 \\
\hline & $25-29$ & 119 & 37.92 \\
\hline & $30-34$ & 32 & 10.19 \\
\hline & $\geq 35$ & 6 & 1.9 \\
\hline & Total & 314 & 100 \\
\hline \multirow{5}{*}{ Ethnicity } & Oromo & 189 & 60.20 \\
\hline & Amahra & 31 & 9.80 \\
\hline & Dawero & 48 & 15.30 \\
\hline & Gurage & 20 & 6.36 \\
\hline & Other (Specify) & 23 & 5.97 \\
\hline \multirow{6}{*}{ Educational Status } & Illiterate & 30 & 9.55 \\
\hline & Can read and write & 50 & 15.92 \\
\hline & Grade & & \\
\hline & $1-6$ & 72 & 22.93 \\
\hline & $7-12$ & 110 & 35 \\
\hline & College/University & 52 & 16.6 \\
\hline \multirow{5}{*}{ Marital Status } & Single & 10 & 3.18 \\
\hline & Married & 253 & 80.57 \\
\hline & Divorced & 31 & 9.87 \\
\hline & Widowed & 21 & 6.68 \\
\hline & Total & 314 & \\
\hline \multirow{5}{*}{$\begin{array}{l}\text { Husband } \\
\text { Educational Status }\end{array}$} & Illiterate & 8 & 3.18 \\
\hline & Can read and write & 27 & 10.7 \\
\hline & Grade 1-6 & 45 & 17.83 \\
\hline & Grade $7-12$ & 90 & 35.7 \\
\hline & College/University & 83 & 32.8 \\
\hline \multirow{5}{*}{ Occupational Status } & House Wife & 120 & 38.21 \\
\hline & Farmer & 18 & 5.7 \\
\hline & Governmental Employee & 82 & 26.11 \\
\hline & Student & 35 & 11.15 \\
\hline & Merchant & 60 & 19.1 \\
\hline \multirow{5}{*}{ Religion } & Muslim & 132 & 42 \\
\hline & Orthodox & 120 & 38.2 \\
\hline & Protestant & 40 & 12.7 \\
\hline & Waqafata & 8 & 2.54 \\
\hline & Catholic & 14 & 4.4 \\
\hline \multirow{4}{*}{$\begin{array}{l}\text { Monthly } \\
\text { Income } \\
\text { (in birr) }\end{array}$} & $<1000$ birr & 40 & 12.74 \\
\hline & $1001-2000$ & 98 & 31.2 \\
\hline & $2001-3000$ & 122 & 38.85 \\
\hline & $>3000$ & 54 & 17.2 \\
\hline
\end{tabular}

\section{Discussion}

Most of respondents were belong to age group of 20-34 years. Likewise study conducted in India and Wolayitasodo, southern Ethiopia, were majority of ANC attenders were from the age group 20-34 years-old
[9-11]. In contrast to this in Puducherry, South India, majority were in the age group of 20-24 years [1]. From this study majority of study population were literate, likewise study conducted in Wolayita Sodo town and Adama Hospital Medical College in which majority were literate $[10,12]$. Majority of study participants were 


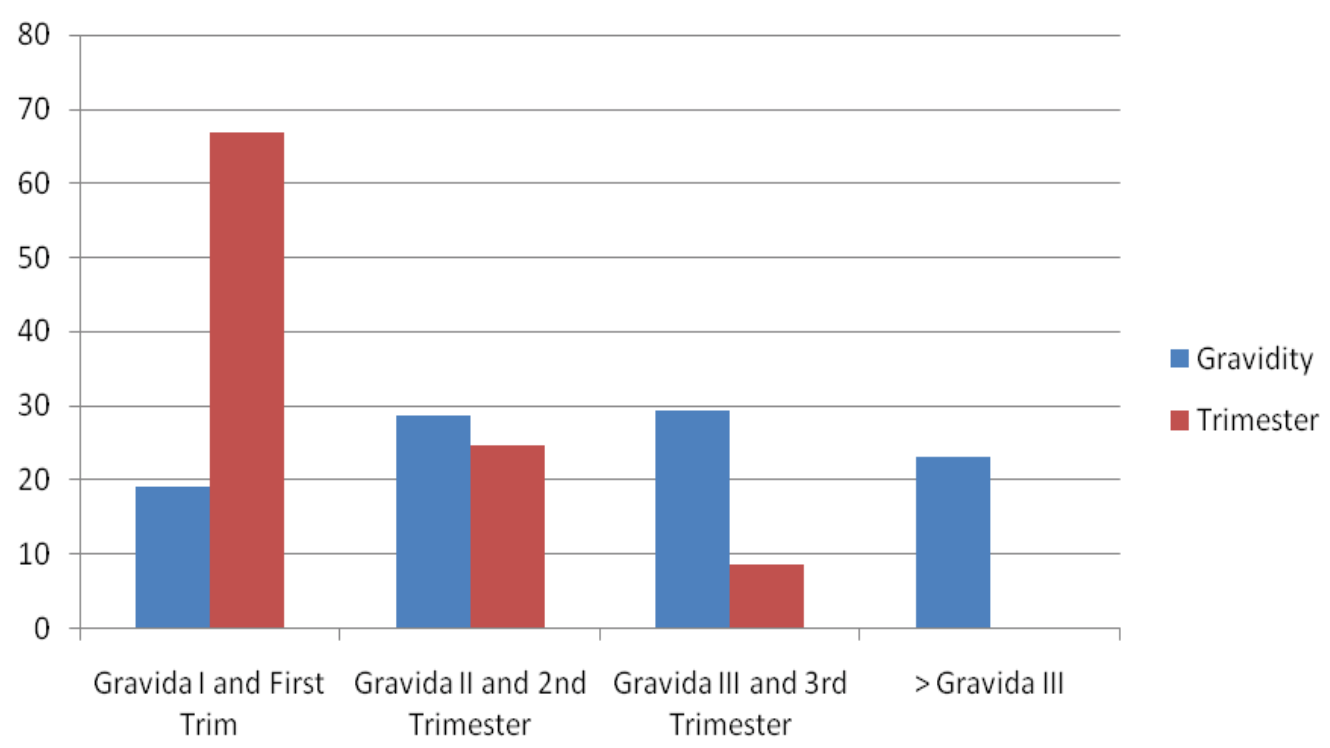

Figure 1: Distribution of pregnant mother who attended ANC department of JMC by gravidity and gestational age at $1^{\text {st }}$ visit Jimma town, south western Ethiopia, 2019.

\section{Risk Factors of Index Pregnancy}

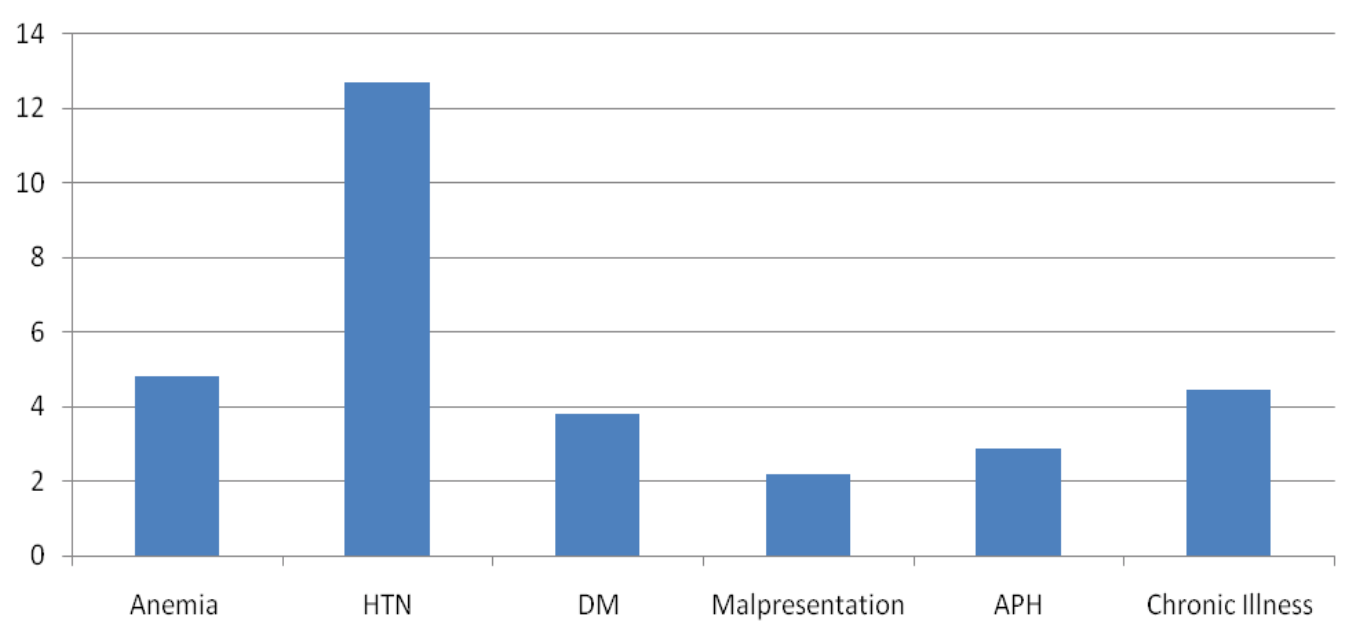

Figure 2: Distribution of pregnant mother who attended ANC department of JUMC by high risk in index pregnancy, Jimma town, south western Ethiopia, 2019.

Table 2: High risk pregnant mother and associated factors of women attended ANC department of JMC, Jimma town, South Western Ethiopia, 2019.

\begin{tabular}{|c|c|c|c|c|c|}
\hline \multicolumn{2}{|l|}{ Variable } & \multirow{2}{*}{$\begin{array}{l}\text { High risk women } \\
4\end{array}$} & \multirow{2}{*}{\begin{tabular}{|l} 
Not at high risk women \\
43
\end{tabular}} & \multirow{2}{*}{$\begin{array}{l}X^{2} \\
37.349\end{array}$} & \multirow{2}{*}{$\begin{array}{l}P \text { value } \\
0.0000\end{array}$} \\
\hline Age & $15-19$ & & & & \\
\hline & $20-24$ & 23 & 87 & & \\
\hline & $25-29$ & 32 & 87 & & \\
\hline & $30-34$ & 19 & 13 & & \\
\hline & $>34$ & 5 & 1 & & \\
\hline \multirow[t]{5}{*}{ Occupational status } & House wife & 25 & 85 & \multirow[t]{5}{*}{15.137} & \multirow[t]{5}{*}{0.0044} \\
\hline & Farmer & 3 & 15 & & \\
\hline & Government employ & 35 & 47 & & \\
\hline & Student & 5 & 30 & & \\
\hline & Merchant & 15 & 45 & & \\
\hline
\end{tabular}




\begin{tabular}{|c|c|c|c|c|c|}
\hline \multirow[t]{5}{*}{ Religion } & Muslim & 39 & 73 & \multirow[t]{5}{*}{3.737} & \multirow[t]{5}{*}{0.4428} \\
\hline & Orthodox & 30 & 80 & & \\
\hline & Protestant & 10 & 30 & & \\
\hline & Catholic & 3 & 11 & & \\
\hline & Wakefata & 1 & 7 & & \\
\hline \multirow[t]{3}{*}{ Trimester } & First & 22 & 188 & \multirow[t]{3}{*}{84.224} & \multirow[t]{3}{*}{0.0000} \\
\hline & Second & 43 & 34 & & \\
\hline & Third & 18 & 9 & & \\
\hline \multirow[t]{4}{*}{ Parity } & Gravid one & 9 & 51 & \multirow[t]{4}{*}{12.517} & \multirow[t]{4}{*}{0.0058} \\
\hline & Gravid two & 17 & 73 & & \\
\hline & Gravid three & 30 & 63 & & \\
\hline & $>$ gravid three & 27 & 46 & & \\
\hline \multirow[t]{5}{*}{ Educational status } & Illiterate & 22 & 8 & \multirow[t]{5}{*}{80.765} & \multirow[t]{5}{*}{0.0000} \\
\hline & Can read and write & 28 & 22 & & \\
\hline & Grade 1-6 & 12 & 60 & & \\
\hline & Grade 7-12 & 8 & 102 & & \\
\hline & College/university & 13 & 39 & & \\
\hline \multirow[t]{4}{*}{ Monthly income in birr } & $\leq 1000$ & 25 & 15 & \multirow[t]{4}{*}{34.970} & \multirow[t]{4}{*}{0.0000} \\
\hline & $1001-2000$ & 28 & 70 & & \\
\hline & $2001-3000$ & 21 & 101 & & \\
\hline & $>3000$ & 9 & 45 & & \\
\hline
\end{tabular}

\section{Previous Risk Factors}

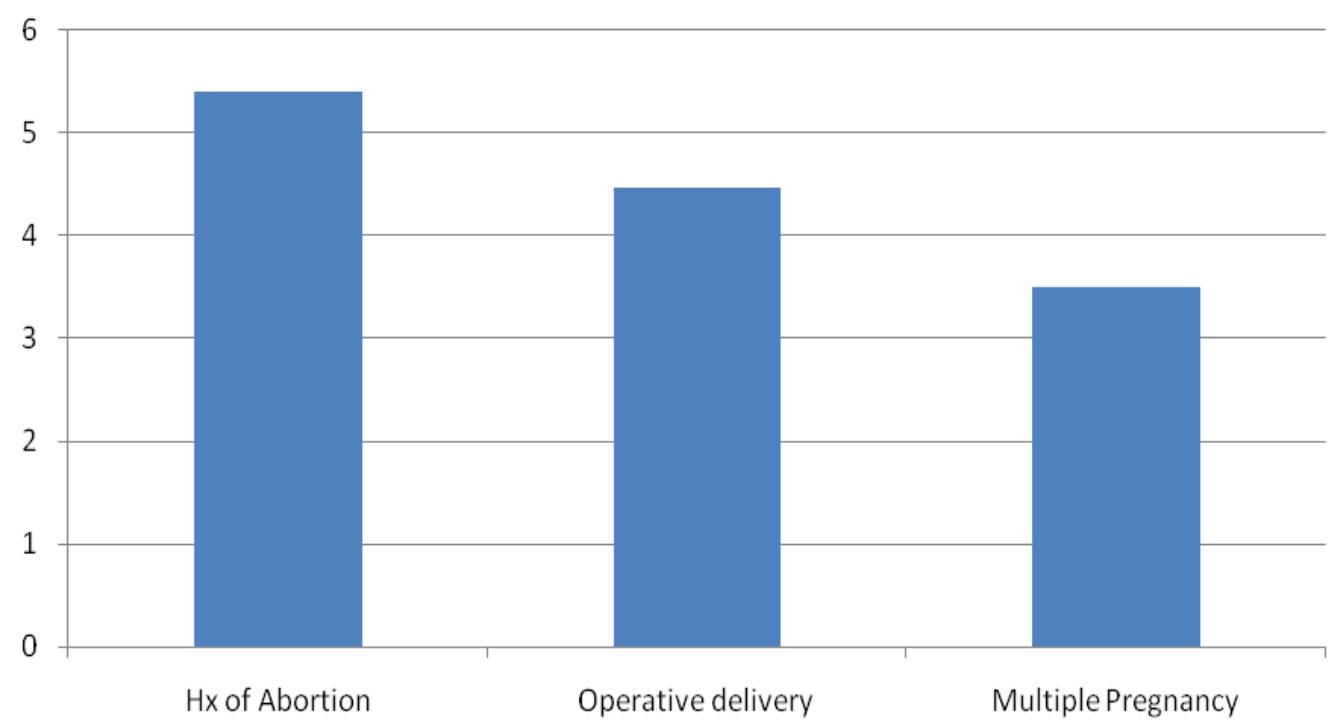

Figure 3: Distribution of pregnant mother who attended ANC department of JUMC by previous risk factor, Jimma town, south western Ethiopia, 2019.

married likewise that of in Tanzania, western Ethiopia, and Boditi Health center $[6,10,13]$.

This study show that majority of women registered their current pregnancy within the first trimester, likewise that of study conducted in Puducherry, South India and Adama hospital medical college $[1,7]$. But this figure is high when it compared to the study done in Saudi which majority of them visit at second and third trimester this may be due to socio cultural and economic difference and also the time gap between the two researches done.

This study demonstrated that the prevalence of high risks among women who attended ANC department of JMC was found to be $26.43 \%$. In congruent to this study, From study conducted in Pondicherry, South India, other Two India areas, Kalaivani $\mathrm{S}$ and His colleague's 


\section{Family History of Chronic Diseases}

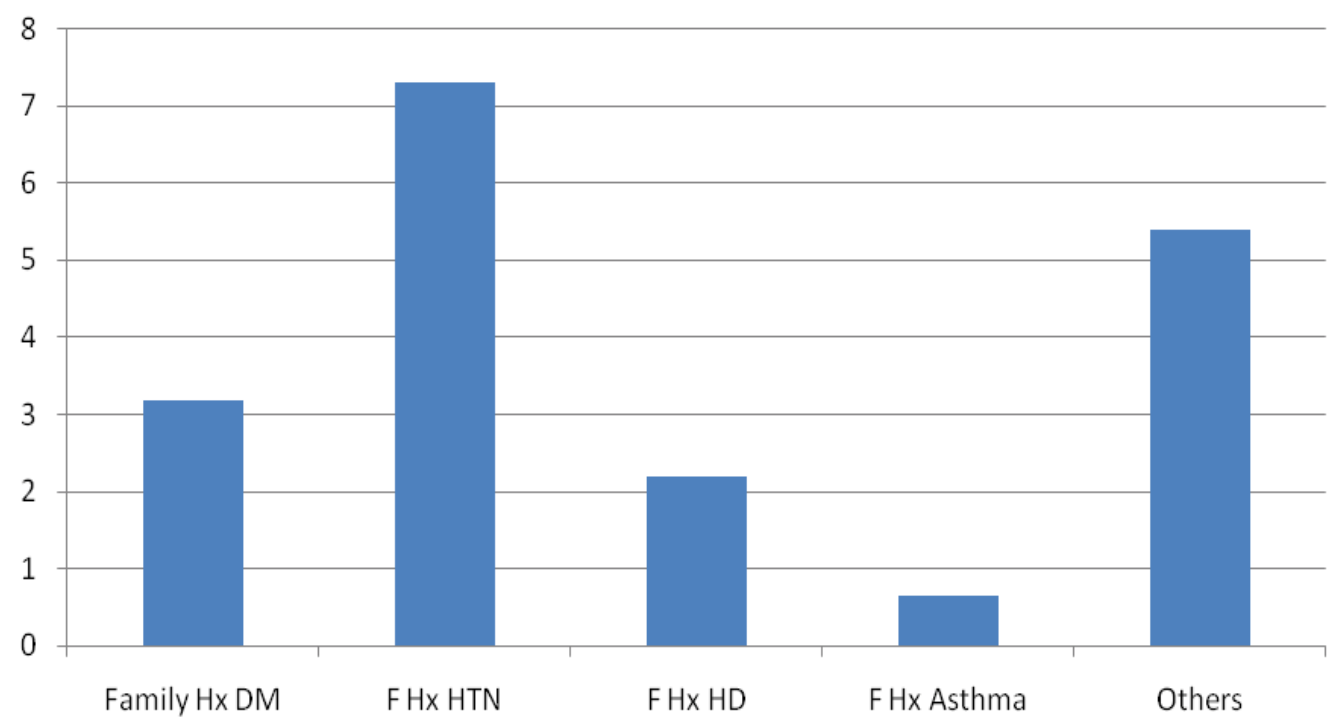

Figure 4: Distribution of pregnant mother who attended ANC department of JMC by family Hx of chronic Ds Jimma town, south western Ethiopia, 2019.

\section{History of Sabstance use}

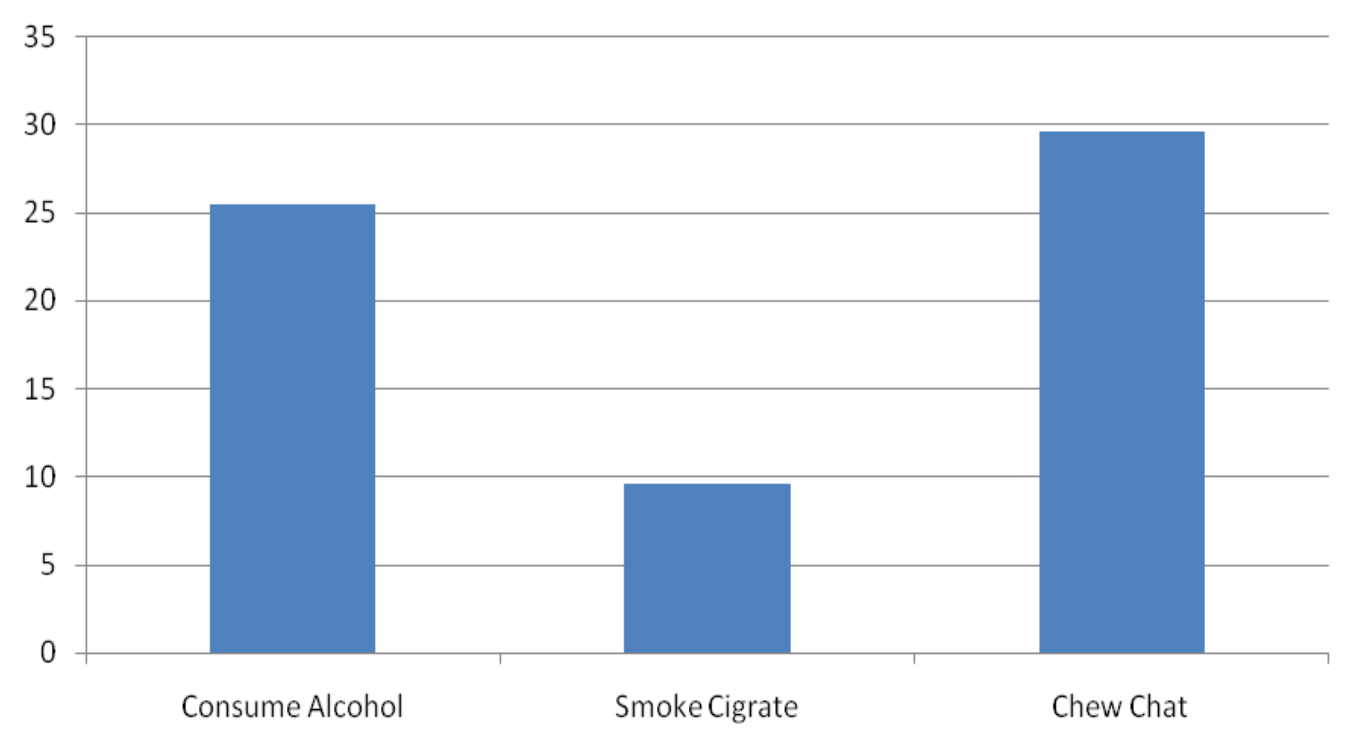

Figure 5: Distribution of pregnant mother who attended ANC department of JMC by Hx of substance abuse Jimma town, south western Ethiopia, 2019.

prevalence of high risk pregnancy were $18.3 \%, 30 \%$, $28 \%, 20-30 \%$, respectively $[1,2,9,14]$. In contrast to this finding in Saudi and other specific area of India prevalence of high risk pregnancy were $44 \%$ and $63.3 \%$ respectively [3,9].

In this finding the leading high risk identified in the index pregnancies were HTN (12.7\%), anemia (4.8\%), DM (3.8\%), APH (2.87\%), and mal presentation $2.2 \%$. Likewise study in Puducherry, South India, also other study in India, Kalaivani $\mathrm{S}$ and His colleague's hypertension disorder in pregnancy were the leading high risk pregnancy $[1,2,14]$, But this finding is very high compared to study conducted in western Ethiopia [10]. In contrast to this in Saudi, Western Ethiopia, Boditi Health Center, Wolayita Town anaemia is the leading high risk identified $[3,10,13,15]$. Also these figures are high when they compared to this finding.

Prevalence of anemia is by far small in JMC compared to those researches mentioned above. This difference may due to the discrepancy of the place where study was conducted. And also in JMC Pregnant women start taking Iron supplementation during their first visit. In this finding prevalence of DM $(3.8 \%)$, which relatively similar with that of Puducherry, South India, and 


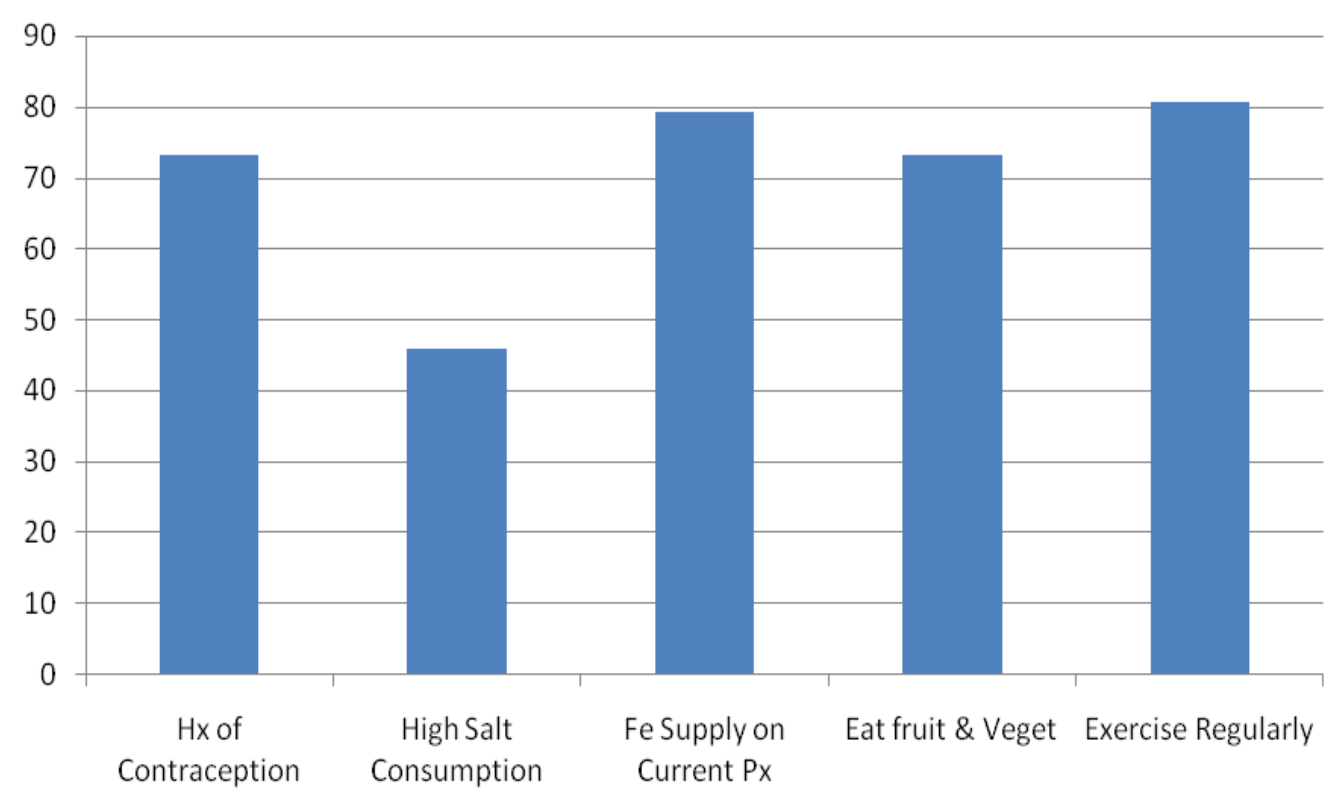

Figure 6: Distribution of pregnant mother who attended ANC department of JMC by Hx of contraception, dietary and life style Jimma town, south western Ethiopia, 2019.

\section{BMI of Women}

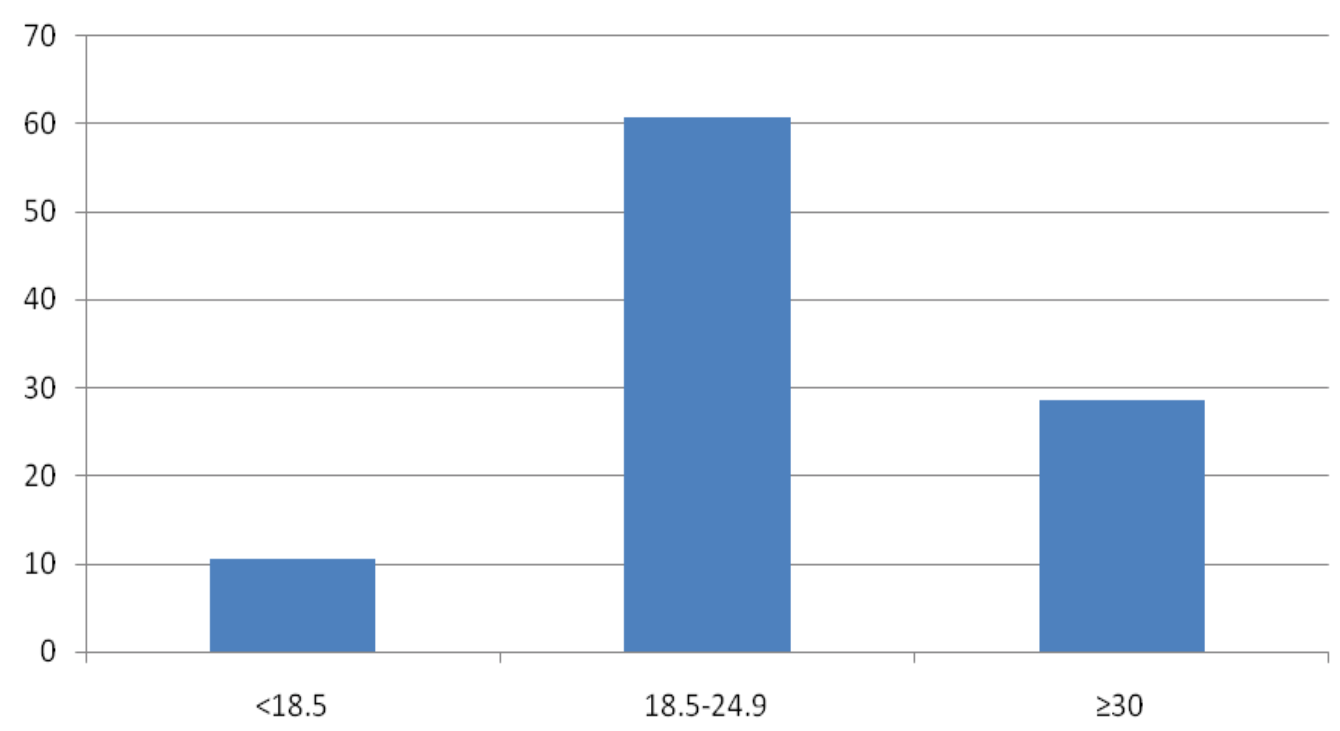

Figure 7: Distribution of pregnant mother who attended $\mathrm{MCH}$ department of JMC by BMI Jimma town, south western Ethiopia, 2019.

Kigali City, Rwanda $[1,16]$. But less than that of Saudi and Kuwait $[3,12]$. Regarding the previous pregnancy, abortion (5.41\%) was most common problem likewise that of in Saudi and Kalaivani S and His colleagues [3,14]. But in Puducherry, South India previous history of LUST C/S [1].

\section{Strength and Limitations}

The researcher uses maximum sample size to increase representativeness of the study subjects. There were no researches done in the same title at the same study area. This cross sectional study has possible limitations that may arise from pregnant women's readiness and ability to provide every information about themselves and their family correctly and recall bias may be is introduced during data collection from the pregnant women as they were self-referred.

\section{Conclusions}

From the total of study participant's the prevalence of high risk were $26.43 \%$. Hypertension (12.7), anemia (4.8\%), DM (3.8\%), APH (2.87\%) and malpresentation (2.2\%) founded as the major health problems. High risk pregnancy shows a significant association with age, occupational status, trimester, parity, educational status, and monthly income. 


\section{Competing Interests}

The authors declare that they have no competing interests.

\section{Authors' Contributions}

$\mathrm{JN}$ involved in designing of the study, data collection, data analysis, drafting and critically reviewing the manuscript. Likewise, MD and MG involved in designing of the study, analysis of the data and critically reviewing the manuscript. All authors read and approved the final manuscript.

\section{Consent for Publication}

Consent for publication is not applicable since there are no details, images, or videos relating to an individual person in this study.

\section{Funding}

This study was funded by Jimma University in partial fulfillment of the requirement for BSc degree in midwifery.

\section{Author Details}

$\mathrm{JN}$ is lecturer of maternal health nursing in institute of health Jimma University, MD is a graduate assistance II in institute of health, Dilla University and MG is lecturer of maternal health nursing in institute of health Jimma University. All authors are currently staff members in their respective department in Jimma University and Dilla University.

\section{Acknowledgements}

We would like to acknowledge Jimma University for giving us the opportunity to do this research. We also acknowledge the data collectors and Jimma Medical Center.

\section{References}

1. Majella MG, Sarveswaran G, Krishnamoorthy $Y$, Sivaranjini K, Arikrishnan K, et al. (2019) A longitudinal study on high risk pregnancy and its outcome among antenatal women attending rural primary health center in Puducherry, South India. J Educe Health Promote 8: 12.

2. Jaideep KC, Prashant D, Girija A (2017) Prevalence of high risk among pregnant women attending antenatal clinic in rural field practice area of Jawaharlal Nehru Medical College, Belgavi, Karnataka, India. Int J Community Med Public Health 4: 1257-1259.

3. Hafez SK, Sh Dorgham L, AM Sayed S (2014) Profile of high risk pregnancy among saudi women in Taif-KSA. World Journal of Medical Sciences 11: 90-97.
4. World Health Organization (2016) WHO recommendations on antenatal care for a positive pregnancy experience.

5. Chemir F, Alemseged F, Workneh D (2014) Satisfaction with focused antenatal care service and associated factors among pregnant women attending focused antenatal care at health centers in Jimma town, Jimma zone, South West Ethiopia; a facility based cross-sectional study triangulated with qualitative study. BMC Res Notes 7: 164.

6. MacLeod J, Rhode R (2007) Retrospective follow-up of maternal deaths and their associated risk factors in a rural district of Tanzania. Trop Med Int Health 3: 130-137.

7. Ayano B, Amentie B (2018) Assessment of prevalence and risk factors for anemia among pregnant mothers attending Anc clinic at Adama hospital medical college, Adama, Ethiopia, 2017. Journal of Gynaecology and Obstetrics 6: 31-39.

8. Tesfaye AG, Tefera BL, Sena BK (2018) Pregnancy induced hypertension and associated factors among pregnant women receiving antenatal care service at Jimma Town Public Health Facilities, South West Ethiopia. J Gynecology Women's Health 10: 555792.

9. Yeoh PL, Hornetz K, Dahlui M (2016) Antenatal care utilization and content between low-risk and high-risk pregnant women. PLoS One 11: e0152167.

10. Gedefaw L, Ayele A, Asres Y, Mossie A (2015) Anaemia and associated factors among pregnant women attending antenatal care clinic in Wolayita Sodo Town, Southern Ethiopia. Ethiop J Health Sci 25: 155-162.

11. Lebso M, Anato A, Loha E (2017) Prevalence of anemia and associated factors among pregnant women in Southern Ethiopia: A community based cross-sectional study. PLoS One 12: e0188783.

12. Groof Z, Garashi G, Husain H, Owayed S, AlBader S, et al. (2019) Prevalence, risk factors, and fetomaternal outcomes of gestational diabetes mellitus in Kuwait: A Cross-Sectional Study. Journal of Diabetes Research 2019: 9136250.

13. Lelissa D, Yilma M, Shewalem W, Abraha A, Worku M, et al. (2016) Prevalence of anemia among women receiving antenatal care at Boditii Health Center, Southern Ethiopia. Clinical Medicine Research 4: 79-86.

14. Kalaivani S, Saradhambal M, Revathy D (2016) Prevalence of high risk pregnancy - A descriptive study. Int $\mathrm{J}$ of Adv Res 4: 1220-1224.

15. Eyasu E, Alemnew B, Fikadu A, Fikadu M, Tesfaye L, et al. (2014) Prevalence of anemia in pregnant women and associated risk factors in western Ethiopia. Food Science and Quality Management 31: 20.

16. Niyibizi JB, Safari F, Ahishakiye JB, Habimana JB, Mapira H, et al. (2016) Gestational diabetes mellitus and its associated risk factors in pregnant women at selected health facilities in Kigali City, Rwanda. Journal of Diabetes Mellitus 6: 269-276. 